\title{
INTEGRAÇÃO CURRICULAR NO IFES: LIMITES E POSSIBILIDADES DA PESQUISA-AÇÃO ${ }^{12}$
}

\author{
Marcelo Lima ${ }^{3}$ \\ Renan dos Santos Sperandio ${ }^{4}$ \\ Samanta Lopes Maciel ${ }^{5}$ \\ Zilka Teixeira ${ }^{6}$
}

\section{Resumo}

Neste trabalho, foi analisado a pesquisa-ação no contexto da integração curricular do ensino médio à educação profissional na Rede Federal. Identificou-se a emergência de uma "resistência muda" dos sujeitos envolvidos que por meio de discursos e práticas destoantes apoiaram, mas também boicotaram a pesquisaação, resultando na descontinuidade da mobilização e do envolvimento dos grupos focais. De todo modo, houve êxito no campo do diagnóstico e da formação docente e os resultados futuros são promissores para os objetivos do estudo.

Palavras-chave: Ensino médio integrado; Pesquisa-ação; Rede federal.

\begin{abstract}
In this work, the action research was analyzed in the context of the curricular integration of secondary education to professional education in the Federal Network. It was identified the emergence of a "silent resistance" of the involved subjects that by means of discourses and distoantes practices supported, but also they boycotted the action research, resulting in the discontinuity of the mobilization and the involvement of the focal groups. However, there has been success in the field of teacher diagnosis and training, and future results are promising for the study objectives.
\end{abstract}

Keywords: Integrated secondary education, Action research, Federal education system.

\section{Introdução}

A oferta universal do ensino médio de qualidade integrado à educação profissional técnica de nível médio à escolha dos estudantes como opção formativa representa avanço na "luta pela superação do dualismo estrutural da

\footnotetext{
${ }^{1}$ DOI: https://doi.org/10.22409/tn.16i29.p4649

${ }^{2}$ Texto originalmente apresentado no GT09 na 38a reunião anual da anped em outubro de 2017.

${ }^{3}$ Doutor em educação pela UFF, Membro do PPGE-UFES e coordenador do LAGEBES.

${ }^{4}$ Graduado em Pedagogia pela UFES e Mestrando em educação no PPGE-UFES.

${ }^{5}$ Graduada em Pedagogia pela UFES, Mestra em educação e pedagoga do IFES - campus São Mateus.

${ }^{6}$ Graduada em Pedagogia pela UFES e Mestranda em educação no PPGE-UFES - Gerente de educação profissional do Senai-ES.
}

TrabalhoNecessário- www.uff.br/revistatrabalhonecessario: ano 16, №29/2018 
sociedade e da educação" que engendra um currículo escolar calcado na divisão social e técnica do trabalho "em defesa da democracia e da escola pública" (CIAVATTA; RAMOS, 2012, pág. 308).

Essa forma curricular, inviabilizada nos anos 1990 e atualmente combatida pela reforma do ensino médio (Lei $n^{\circ}$ 13.415) ainda vigente nas escolas pelo Brasil, representa importante travessia de uma escola segmentadora e diferenciadora para construção de um currículo escolar baseado na politecnia. Conforme Saviani, embora literalmente a politecnia seja definida como uma "multiplicidade de técnicas", a politecnia que se almeja na concepção de escola e de currículo "diz respeito ao domínio dos fundamentos científicos das diferentes técnicas que caracterizam os processos produtivos modernos" (SAVIANI, 1989, pág. 16) e seu desdobramento político pressupõe uma formação ominilateral que ao contrário de uma formação unilateral, não dicotomiza saberes e sujeitos. Essa concepção se opõe a uma formação exclusiva e restritiva ao trabalho manual ou ao trabalho intelectual; transita, portanto, do trabalho simples ao trabalho complexo para formar o técnico e o cidadão.

A formação omnilateral leva em conta todas as dimensões que constituem a especificidade do ser humano e tem como contexto as condições objetivas e subjetivas reais dos educandos para seu pleno desenvolvimento. Essas dimensões envolvem sua vida corpórea material e seu desenvolvimento intelectual, cultural, educacional, psicossocial, afetivo, estético e lúdico" (FRIGOTTO, 2012, pág. 267).

Uma escola politécnica deve operar no horizonte da superação das polaridades e hierarquias presentes no currículo escolar entre conhecimento geral e conhecimento específico, entre saber técnico-prático e saber político-humanista. Para tanto, faz-se necessária a construção de eixos curriculares e nexos integradores capazes de estabelecer ou encontrar possíveis pontos de articulação e organização dos saberes escolares presentes na mesma totalidade concreta. Para realizar uma formação omnilateral, processos, métodos, espaços e tempos de ensino "não podem ser determinados nem pela unilateralidade da teoria nem da prática, mas na unidade dialética de ambas, ou seja, na e pela práxis" (FRIGOTTO, 2010, pág. 192).

Desse modo, o currículo para ser integrado não deve ser compartimentalizado e disciplinar, ou fragmentado em conteúdos isolados. Para

TrabalhoNecessário- www.uff.br/revistatrabalhonecessario: ano 16, №29/2018 
Ramos (2012) a integração deve permitir uma apreensão da realidade em sua totalidade, pois saberes escolares isolados entre si e desprendidos da realidade concreta podem comprometer uma visão mais ampla da produção material e da sociedade (RAMOS, 2012, p. 117). Ou seja, para forjar uma compreensão crítica, científica, filosófica e criativa da realidade exige-se o acesso amplo e articulado dos saberes escolares que representam acervos da humanidade, aos quais devemos ter acesso para construirmos a nossa própria humanidade. Tal possibilidade exige uma escola pública de qualidade que ofereça um currículo integrado com matrícula única na mesma unidade de ensino onde prática, teoria, tecnologia, ciência, história, cultura, linguagem, estética e ética se imbriquem nos espaços e nos tempos, configurando um currículo escolar onde o aluno seja reconhecido em suas múltiplas dimensões tendo em vista seu contexto, mas também no seu vir-a-ser. Para tanto, é necessário conceber o homem como ser histórico e social já que a história da humanidade é a história da produção humana da existência e "a história do conhecimento é a história do processo de apropriação social dos potenciais da natureza, mediada pelo trabalho" e pela educação (RAMOS, 2012, pág. 115).

Nesse entendimento, o trabalho é tomado como princípio educativo, no sentido de que é pelo trabalho que o homem modifica e transforma a natureza e a si mesmo e, nesse intuito, ele é elemento criador da vida humana e como tal apreende, desde a infância, de que é pelo trabalho que o ser humano transforma a natureza em bens úteis à sua sobrevivência. Isso implica a formação do trabalhador numa perspectiva crítica da produção capitalista, afirmando o princípio educativo e emancipador do processo histórico-ontológico da produção material. A partir desses pressupostos, podemos afirmar que a integração emerge de um currículo que se organiza como uma totalidade orgânica que não se reduz à soma das partes. Essa proposta e prática educativa deve se dar numa escola eminentemente pública e unitária, que se baseia na universalidade do direito ao ensino médio e ao ensino técnico cujo público é, e deve ser, heterogêneo (nos seus aspectos social, econômico, geográfico, etário, étnico e cultural). O seu conteúdo tem o trabalho como princípio educativo e deve se organizar e se estruturar por meio de uma matriz curricular politécnica cuja finalidade é a formação omnilateral dos educandos. 
Apesar do contexto atual, em que as mudanças na legislação educacional inseridas com a reforma do ensino médio que indicam em sentido contrário, o ensino médio integrado tem suas bases ainda fundamentadas na Constituição Federal (CF), na Lei de Diretrizes e Bases da Educação (LDB), na lei de criação dos IFs, nas Diretrizes Curriculares Nacionais e no Plano Nacional de Educação (PNE - Lei n. 13.005/14). Para a Constituição de 1988, a educação visa "ao pleno desenvolvimento da pessoa, seu preparo para o exercício da cidadania e sua qualificação para o trabalho" (artigo 205). Segundo a LDB (Lei n. 9394/96), "a educação escolar deve se vincular à prática social e ao mundo do trabalho" (artigo $2^{\circ}$ ). Também nesta lei afirma-se que o ensino médio terá como finalidade "prosseguimento de estudos" e a "preparação básica para o trabalho" de modo a que o educando continue "aprendendo, de modo a ser capaz de se adaptar com flexibilidade a novas condições de ocupação" e que possa compreender "os fundamentos científico-tecnológicos dos processos produtivos" (Incisos de I - IV do artigo 35).

No PNE, a formação integrada aparece como consequência de algumas metas e estratégias. Neste aspecto ganham destaque as estratégias 3.7 (fomentar expansão de matrículas gratuitas de ensino médio integrado à EP), 10.2 (articular EJA e EP para aumentar a escolarização do trabalhador), 10.3 (fomentar a integração EJA e EP) e 11.9 (expandir o EM integrado à EP para as populações do campo, indígenas e quilombolas) que não só legitimam a integração como apontam para sua expansão.

A lei de criação dos IFs (Lei № 11.892/08) assumiu dentre suas principais finalidades: "promover a integração e a verticalização da educação básica à educação profissional" (artigo 6). Cabe então aos IFs "ministrar educação profissional técnica de nível médio, prioritariamente na forma de cursos integrados, para os concluintes do ensino fundamental e para o público da educação de jovens e adultos" (artigo 7).

\section{Desenvolvimento}

Esse artigo tem como fito analisar e problematizar o processo metodológico da pesquisa-ação num Instituto Federal, tendo em vista a necessidade de realização de ações de diagnóstico e de formação, sobre o ensino médio 
integrado. Este estudo vincula-se a uma das ações do projeto de pesquisa que desenvolvido no laboratório de gestão da educação básica do Espírito Santo e do Programa de pós-graduação em Educação da UFES no período de 2013 a $2016^{6}$.

Trata-se de uma análise que buscou fortalecer por meio da pesquisa-açãoformação (primeira fase) e do projeto de intervenção (segunda fase) as práticas de integração (e ou interdisciplinares) no processo ensino-aprendizagem do EM integrado à EPTNM. Além de avaliar e promover atividades coletivas de ensino, pesquisa e extensão, com vistas à convergência dos sujeitos (alunos, professores e gestores) e dos saberes nos espaços e nos tempos.

A pesquisa-ação (formação e intervenção) se desenvolveu por quatro anos (2013-2016), abrangeu sete campi (Vitória, Venda Nova do Imigrante, São Mateus, Cariacica, Guarapari, Barra de São Francisco e Colatina), tendo em vista os cursos técnicos integrados em Agroindústria, Administração, Mecânica, Eletrotécnica e Edificações do ES. Durante o estudo foram realizadas mais de 20 reuniões dos grupos focais e aplicado formulário de diagnóstico da integração para 300 docentes em evento promovido pela pesquisa.

A pesquisa contou com a participação de um coordenador, dois bolsistas ${ }^{7} \mathrm{e}$ três mestrandos que durante seu desenvolvimento acumularam mais de 12 horas de gravações, dois relatórios de iniciação científica, tendo sido percorridos mais de $4000 \mathrm{~km}$ nas visitas aos municípios onde localizam os campi pesquisados.

A instituição em questão, em 2011, possuía 17 campi com uma oferta diversificada que totalizava 16.431 alunos matriculados (BRASIL, 2011). Hoje, com $20 \mathrm{campi}$, atinge aproximadamente $20 \mathrm{mil}$ matrículas, no entanto, a distribuição das matrículas e das vagas entre os campi e as modalidades é muito diversa. Os dados de novas vagas estimados em 2015 para oferta em 2016 reiteram essas assimetrias e indicam que a consolidação da oferta do ensino médio integrado à educação profissional não está garantida, conforme observar na tabela 01.

\footnotetext{
${ }^{6}$ Registro na Pró-Reitoria de pesquisa pós-graduação da UFES - № 4198/2013 e 6068/2015 Registro na Plataforma Brasil - no 14819813.3.3001.5072 - Aprovada pela CEP-UFES em 01/07/2013 - Financiado pelo PIIC 2013-2014/ 2015-2016.

${ }^{7}$ Agradecemos a colaboração das bolsistas de IC Caroline de Abreu Lourenço e Daniele da Silva Pereira
}

TrabalhoNecessário- www.uff.br/revistatrabalhonecessario: ano 16, №29/2018 
Tabela 1 - Oferta de vagas no Ensino Médio Integrado por campi do IFES (2016)

\begin{tabular}{|c|l|l|l|}
\hline CAMPI & VAGAS & \multicolumn{1}{|c|}{ CAMPI } & VAGAS \\
\hline Alegre & 226 & Aracruz & 120 \\
\hline Cachoeiro de Itapemirim & 80 & Cariacica & 220 \\
\hline Centro-Serrano & 120 & Colatina & 144 \\
\hline Guarapari & 104 & Ibatiba & 144 \\
\hline Itapina & 180 & Linhares & 128 \\
\hline Montanha & 80 & Nova Venécia & 144 \\
\hline Piúma & 108 & Santa Tereza & 180 \\
\hline São Mateus & 64 & Venda Nova do Imigrante & 180 \\
\hline Serra & 0 & Viana & 80 \\
\hline Vila Velha & 0 & Vitória & 200 \\
\hline \multicolumn{2}{|l|}{ Total: 2502} \\
\hline
\end{tabular}

Fonte: Instituto Federal do Espírito Santo (2016).

Vale lembrar que a função social da rede federal, ainda, se alicerça juridicamente e politicamente na oferta prioritária do ensino médio integrado à educação profissional técnica de nível médio. Outras redes também oferecem essa forma curricular, mas não possuem, na sua maioria, as mesmas condições financeiras e estruturais da rede dos IFs.

Nesta pesquisa partimos do pressuposto de que o EM integrado à EPTNM é o formato pedagógico mais adequado para formação integral dos educandos e que a rede federal está mais vocacionada para esta oferta. Não obstante, consideramos que a materialização dessa oferta é complexa e problemática, razão pela qual emerge essa pesquisa comprometida com a viabilização de um currículo politécnico que busca uma formação omnilateral.

Ou seja, apesar das dificuldades implicadas no desenvolvimento da integração curricular e dos riscos de justaposição e fragmentação, essa forma curricular possibilita o fortalecimento da reciprocidade entre os saberes escolares e pode propiciar uma formação mais ampla aos educandos. Além de conectá-los à realidade do mundo do trabalho. Ao ensejar a vinculação entre saberes profissionais e conteúdos escolares teóricos e práticos, estimulam uma fundamentação científica e humanista articulada. Esse tipo de currículo permite uma interação orgânica dos saberes articulados como totalidade histórica engendrada na práxis humana.

Longe de ser uma proposta ou prática curricular que atenda plenamente a uma educação emancipatória, esse modelo representa a possibilidade mais efetiva de enfrentamento do dualismo histórico que preconiza uma formação

\footnotetext{
${ }^{8}$ Os campi de Vila Velha e de Serra passaram a ofertar cerca de 40 vagas cada em 2017.
}

TrabalhoNecessário- www.uff.br/revistatrabalhonecessario: ano 16, №29/2018 
humana não unilateral subserviente à divisão social e técnica do trabalho na sociedade capitalista. No entanto, muitas são as questões estruturais, pedagógicas e ideológicas que envolvem o sucesso da integração, bem como sua generalização e consolidação como política pública.

Bremer e Kuenzer (2012), afirmam que a implantação do ensino médio integrado apresenta numerosos "desafios existentes para que a proposta conceitual seja de fato materializada na prática escolar" (p. 01). Silva (2011, p.03) aponta que ainda existem limitações presentes no processo de ensino "derivados, em parte, de interpretações divergentes do que seja integração curricular e da multiplicidade de significados atribuídos à ideia de trabalho como princípio educativo".

Os Institutos Federais, pelas suas características de educação pública de qualidade, representam um lócus privilegiado para implementação e difusão dessa oferta integrada de ensino médio e técnico, razão pela qual esse tipo de estabelecimento tornou-se objeto dessa pesquisa que, fundamentada no materialismo histórico-dialético, assumiu o caráter de pesquisa-ação, especialmente em razão do engajamento dos pesquisadores e autores deste trabalho. Pois a intenção não foi de contemplar e diagnosticar a situação, mas de intervir por meio do diálogo com os profissionais da rede federal, a fim de transformar a realidade educativa.

A construção teórica-metodológica que orienta o processo de pesquisa em tela, parte da concepção de que a ciência é uma produção histórica dos homens inseridos em determinada forma social e de que os homens, ao produzirem os seus meios de sobrevivência e intervirem sobre a natureza, produzem a si e toda a humanidade. Tendo em vista o compromisso com a construção de uma educação politécnica buscou-se, neste estudo, realizar uma investigação referenciada na perspectiva da pesquisa-ação com vistas ao fortalecimento do ensino médio integrado no IFES.

Esse campo de pesquisa, tomado como aspecto do real, estrutura-se como síntese de múltiplas determinações, como materialidade complexa e ponto de partida e de chegada da totalidade histórica e social (CIAVATTA, 2014). Nesse sentido, buscou-se captar as categorias de estudo nas suas relações com a totalidade e com sua concretude historicamente construída, sem perder de vista determinações, tensões e contradições que nela residem:

TrabalhoNecessário- www.uff.br/revistatrabalhonecessario: ano 16, №29/2018 
Cabe precisar o sentido das "determinações": Determinações são traços pertinentes aos elementos constitutivos da realidade [...] Por isso o conhecimento concreto do objeto é o conhecimento de suas múltiplas determinações - tanto mais se reproduzem as determinações de um objeto, tanto mais o pensamento reproduz a sua riqueza (concreção) real (NETTO, 2011, p. 45).

Para tanto, consideramos o materialismo histórico-dialético mais que um método de investigação e de leitura da realidade. Nesse sentido, intencionamos colocar o método de ação para o pesquisador, tendo em vista o compromisso com a transformação da realidade, razão pela qual elegemos a pesquisa-ação como forma privilegiada de investigação. Essa forma de pesquisa se mostra ainda mais coerente com o materialismo histórico-dialético na medida em que se propõe a superar a visão dicotômica sujeito-objeto, propondo aos envolvidos o compromisso ético-político de transformação da realidade pesquisada.

De acordo com Barbier (2007), a pesquisa-ação pressupõe uma mudança de atitude no que se refere a postura acadêmica, levando a uma mudança de atitude filosófica do pesquisador com o mundo. Deste modo, a pesquisa-ação adota um encaminhamento de servir de instrumento de mudança social (BARBIER, 2007, p. 53), possuindo, segundo Thiollent (2003), potencial gerador de conhecimento sobre pesquisador e pesquisados, que figuram juntos como protagonistas do processo de pesquisa na tentativa de esclarecer um problema, com acompanhamento contínuo das partes envolvidas, pretendendo aumentar seu conhecimento sobre esse problema de modo a produzir mudanças.

Para Tripp (2005), a pesquisa-ação configura-se em tentativa permanente e sistematizada de aprimoramento da prática. Essencialmente tem como finalidade o desenvolvimento do sujeito pesquisador a fim de aprimorar sua prática. Por se pretender incidir sobre a prática e envolver os sujeitos da pesquisa, não se deve abrir mão dos rigores teóricos e metodológicos. Ao contrário, recorre-se a esses mesmos elementos de exigência científica para informar e incidir sobre a prática que está em movimento, pois para se produzir a ação ao mesmo tempo em que se pesquisa, e pesquisar ao mesmo tempo em se que age, é necessário manter postura crítica e sistemática.

Zeichner e Diniz-Pereira (2005) afirmam que a pesquisa-ação tem potencial para trazer uma contribuição genuína à melhoria da prática profissional e ao bem

TrabalhoNecessário- www.uff.br/revistatrabalhonecessario: ano 16, №29/2018 
comum, se reforçados os elos da pesquisa-ação com as lutas por justiça social, política e econômica, contendo assim potencial transformador. No caso desta pesquisa, esse potencial transformador concentra-se justamente em pôr em movimento e em reflexão os seus participantes. Na ação-reflexão-transformação de sua própria prática, os educadores tornam-se os agentes genuínos da transformação social. Neste caso, os sujeitos da pesquisa, ao incorporem o conhecimento numa transformação de baixo para cima, podem conciliar os interesses em disputa, potencializando a transformação: fortalecimento do ensino médio integrado no IFES. Assim, o materialismo histórico-dialético como referencial teórico, que afasta metodologias situadas na perspectiva contemplativa, dialoga com a metodologia da pesquisa-ação, como possibilidade metodológica que compromete o pesquisador no processo de produção de conhecimento e na transformação da realidade.

Depois de uma fase de estudos e primeiros contatos com o IFES, iniciouse, nos primeiros meses de 2013, um trabalho de mobilização e organização dos grupos focais em cada curso técnico tomando como base o campus Vitória nos cursos técnicos em Eletrotécnica e em Edificações.

No segundo semestre de 2013, em função de demanda de formação apresentada pelo campus Vitória, foi organizado um seminário de formação pedagógica sobre o tema da integração curricular que contou com a participação de mais de 300 professores e gestores do IFES que fortaleceu o processo de pesquisa possibilitando produção de material de formação sobre o tema.

No ano de 2014, as ações da pesquisa foram ampliadas para o campus Venda Nova do Imigrante, onde foi constituído um grupo focal com docentes dos cursos técnicos integrados em Administração e em Agroindústria. Nesse mesmo ano, as atividades da pesquisa também foram iniciadas em São Mateus onde também foi composto um grupo com os docentes dos cursos técnicos integrados em Eletrotécnica e em Mecânica.

A partir de 2015, a pedido dos campi Cariacica e Barra de São Francisco iniciamos o trabalho de formação e de pesquisa também nesses campi. Finalmente no ano de 2016, o trabalho de pesquisa foi ampliado para os campi de Guarapari e Colatina.

As reuniões realizadas nos campi e os questionamentos decorrentes foram fundamentais para a construção do entendimento do movimento do real da 
implantação da integração curricular a partir das concepções e avaliações da integração realizadas por parte dos participantes. Foi fundamental ainda para discutirmos o processo de pesquisa a partir das demandas dos participantes e das tentativas de intervenção produzidas. No processo de pesquisa foram realizadas 07 Reuniões em Vitória, 06 em São Mateus, 04 em Venda Nova do Imigrante, 03 em barra de são Francisco, 02 em Cariacica e 01 em Guarapari.

Iniciamos o trabalho de pesquisa-ação articulando com a equipe pedagógica e coordenação dos cursos em cada Campi e posteriormente solicitamos autorização para a pesquisa aos diretores dos campi de Vitória, Venda Nova do Imigrante, Colatina, São Mateus e Guarapari para dar início a pesquisa. Além disso, no decorrer da pesquisa recebemos o convite dos diretores dos campi de Barra de São Francisco e Cariacica.

Além das reuniões com os grupos focais realizamos ações de formação a pedido dos campi. Promovemos um seminário aberto no campus Vitória em outubro de 2013 (convidados Marise Ramos, Dante Moura, Suzana Bournier, Carlos Artexes Simões e Maria Ciavatta) e aplicação de formulário sobre integração dos sujeitos e disciplinas. Também realizamos seminários internos de formação pedagógica sobre a integração em São Mateus (2014), Venda Nova do Imigrante (2014) e Guarapari (2016). Houve a difusão do conhecimento sobre o tema com filmagem das palestras (you tube) e indicações de literatura específica com transcrição das palestras e publicação de dossiê no caderno de pesquisa do PPGE-UFES.

Durante as reuniões dos grupos focais compostos em cada campus, foram levantadas várias questões que buscavam compreender os processos de construção da integração. Os relatos coletados nos encontros expressam diversas concepções sobre a educação integral, a função social da integração e as dificuldades encontradas para a implementação da integração nos cursos ofertados pela instituição.

Ao analisarmos o funcionamento da integração curricular com base na aplicação dos formulários e dos relatos, constatamos que o conhecimento recíproco dos profissionais da área técnica e propedêutica é frágil. Segundo as falas dos docentes, isso tem a ver com a rotatividade de professores do núcleo básico que atuam em vários lugares ao mesmo tempo, o que dificulta a participação, pois não possuem foco no curso em que atuam, como declara um

TrabalhoNecessário- www.uff.br/revistatrabalhonecessario: ano 16, №29/2018 
docente. Ou seja, quando se troca muito de professores na área propedêutica ou se atua em vários cursos, a integração entre as pessoas fica prejudicada, e o ensino integrado fica fragilizado.

\begin{abstract}
Não sei nem quem é. Por que a gente tem alguns problemas aqui que em algumas disciplinas muda quatro vezes o professor de matemática durante o ano [...], é meio complicado a gente tentar fazer uma integração se as pessoas estão atuando em muitos locais. Então eles nunca estão aqui pra discutir por que tem as suas atribuições em outros locais [...].
\end{abstract}

Além disso, a configuração híbrida do IFES, na qual os profissionais atuam em cursos muito diversos (da pós-graduação aos cursos qualificação, passando pela graduação e pelos cursos técnicos, além da pesquisa e da extensão) colabora com um possível movimento de descontinuidade na convivência e na continuidade dos trabalhos desenvolvidos no EM integrado à EPTNM.

Embora as matrizes curriculares dos planos pedagógicos dos cursos sejam documentos acessíveis nos quais estão explicitados os conteúdos de ensino dos cursos técnicos integrados, segundo as respostas dos formulários, nem todos os docentes informam saber que conteúdos os seus respectivos alunos estão aprendendo numa determinada turma/curso/ano/série. Infere-se, com base nos relatos e informações dos formulários que há uma tendência do professor se preocupar apenas com o seu fazer individual, compartilhando pouco suas sequências didáticas com os demais docentes que ensinam nas mesmas turmas.

De outro lado, para a administração, a oferta do EM integrado à EPTNM exige uma postura administrativa diferente que instaure práticas mais coletivas e colaborativas no sentido de integrar e mobilizar a todos em torno do mesmo projeto educativo, indagando e avaliando permanentemente como o currículo se desenvolve na prática.

$\mathrm{Na}$ ausência de uma gestão comprometida com a integração, os docentes vendo as dificuldades, ficam isolados em seus esforços contra e a favor da integração. Deste modo, os docentes se esforçam e apresentam, por meio de suas visões e de suas práticas, o valor que conferem à integração.

Para revelar estes aspectos, primeiro buscamos trazer quais eram as concepções dos professores sobre a integração e como enxergavam esse tema. 
A integração não significa ensino médio integrado ao ensino técnico. Integração acontecia quando você tinha um mesmo cientista que faz matemática, música, escrevia livros, etc. Hoje em dia a integração acontece nas universidades dos Estados Unidos e Europa com pessoas que aprendem desde a física até cozinhar. Isso é integração. (Grupo focal 01 - Vitória / Eletrotécnica 13/03/2013).

A fala acima, proferida na reunião registrada na imagem 01, reflete uma compreensão de integração em uma perspectiva de formação omnilateral; ou seja, formar um sujeito com uma amplitude de saberes.

\section{Imagem 1 - Grupo focal realizado no campus Vitória/Cursos de Eletrotécnica}

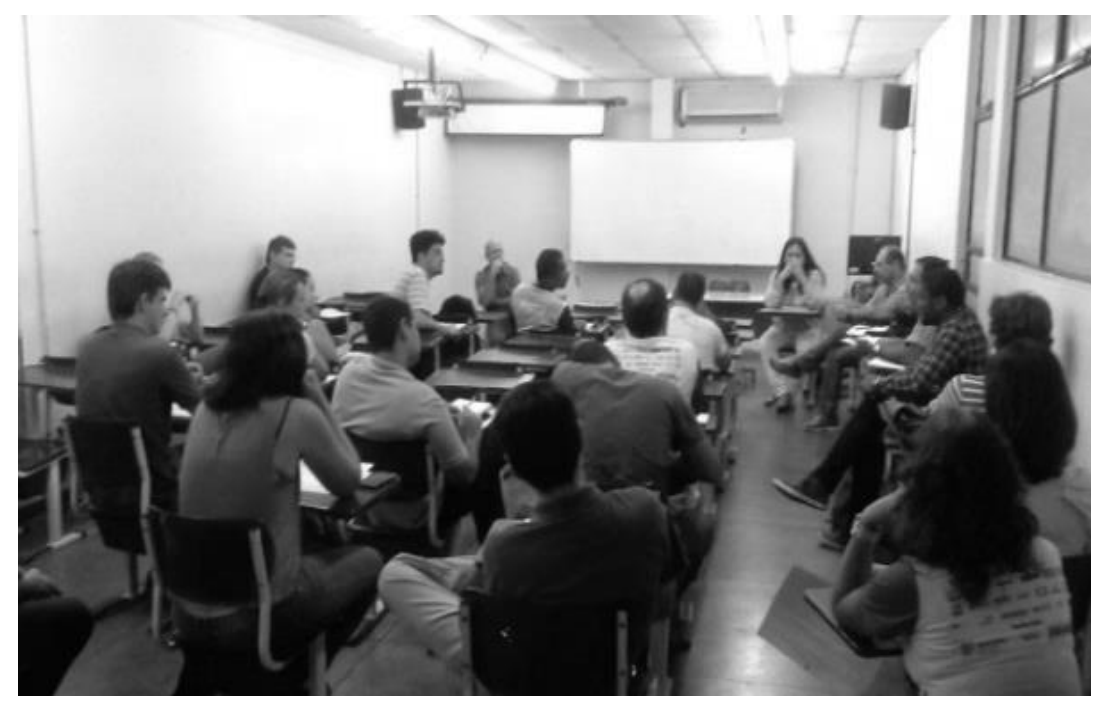

Fonte: Acervo fotográfico do grupo de pesquisa. (13\03\2013)

Para os sujeitos da pesquisa, a prática da integração surge ainda como uma possibilidade para facilitar a compreensão dos alunos sobre temas das disciplinas, como observamos no relato que segue:

Trabalhei com os alunos no ensino médio esse bimestre a integração das etapas do projeto arquitetônico inseridas na química, na física, na matemática, no português então eles enxergavam o que tinha de química quando eu faço um projeto arquitetônico e o que tinha de física, e eles conseguiam enxergar bastante coisa até mais que eu (Grupo focal 02 - Vitória / Edificações - 27/03/2014).

Para promover a integração, os professores por meio de suas aulas vão estimulando os alunos para que este faça mentalmente a relação entre os conteúdos aprendidos de todas as outras disciplinas, produzindo uma integração 
a ser articulada pelos próprios alunos o que não assegura que essa articulação seja feita da forma esperada.

Ainda nesse sentido, um docente afirmou que mesmo ministrando disciplinas em separado, as coisas se juntam no final: "A gente deixa para a cabeça do aluno fazer o processo inverso, de juntar. Esse juntar aí é que pra mim é integrar. É algo bem amplo" (Grupo focal 01 - Vitória / Eletrotécnica 3/12/2014).

Paradoxalmente os docentes identificam que a "desarticulação" dos saberes traz problemas para apropriação do conhecimento. Alguns relatos indicam que os alunos após formados, quando se inserem no mercado de trabalho, possuem dificuldades em compreender determinado processo no seu todo e alguns até voltam para pedir orientações.

O aluno ele é formado e um ou dois meses depois ele volta pra pedir que a gente faça alguma coisa que ele aprendeu e que era básico, dizendo que não sabe fazer (Grupo focal 01-Vitória / Eletrotécnica - 03/12/2014).

Isso mostra o quanto a falta de integração entre os conteúdos pode gerar lacunas na formação dos alunos, pois se espera que eles façam as interconexões entre as disciplinas escolares por conta própria. Durante a pesquisa surgiram falas que evidenciaram a importância da integração da vida escolar com a vida profissional e pessoal dos alunos. Muitos professores afirmaram que apesar da importância das disciplinas previstas na matriz curricular, havia outras vivências e experiências que o instituto garantia aos alunos e que se constituíam em saberes a serem levados para a vida.

As visões sobre a integração curricular, manifestas nos grupos focais, informam as muitas dificuldades de compreensão dos conceitos relativos a esse tema tão debatido no âmbito da produção acadêmica. Trata-se do conceito de trabalho no sentido ontológico.

Quando eu falei no conselho de classe da concepção ontológica do trabalho né, que é.... ai os meninos riram né. - Que diabo de ontológica é isso? A importância que esse fazer manual também tem na vida do sujeito. O sujeito vai ser médico e fica fazendo bolinho de assar? Mas isso tem uma importância na vida dele enquanto sujeito, enquanto cidadão, essa é a concepção. O ser 
humano se dá pelo trabalho (Grupo focal 03 - Venda Nova 23/03/2013).

Alguns acreditam que a validade da integração passa por outro caminho que tem como prioridade formar o cidadão, formado em sua plenitude o que ultrapassa uma formação meramente técnica:

O objetivo nosso aqui não é desenvolver o menino aqui pro mercado de trabalho, é desenvolver o cidadão. Se ele for pro mercado de trabalho beleza, se ele não for, que ele seja um cidadão... (Grupo Focal 04 - São Mateus -01/12/2014).

Imagem 2 - Grupo focal realizado no campus São Mateus (2014)

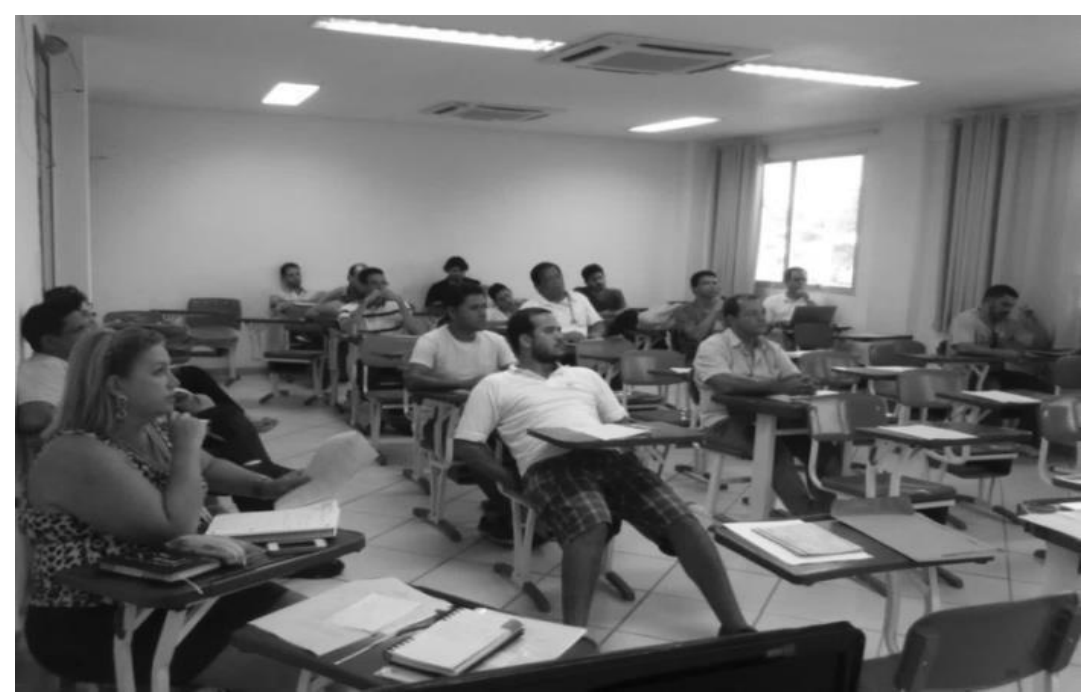

Fonte: Acervo fotográfico do grupo de pesquisa. 1\12\2014)

Ganha relevância na avaliação da integração a gestão da integração. Para os sujeitos da pesquisa, presentes na reunião registrada pela imagem 02, esse aspecto pode interferir no processo de integração curricular favorecendo ou não a integração das pessoas, dos tempos, dos espaços e dos conteúdos de ensino na instituição.

Como se sabe, a oferta de cursos técnicos integrados está amparada tanto na Constituição Federal, na LDB, nas Diretrizes Curriculares Nacionais, quanto, na Lei que cria os IFs. De modo mais particular, do ponto de vista local também há uma série de prescrições apresentadas em plano de ensino, regimento e estatuto da instituição. Mas, segundo os relatos, em nenhum lugar há orientações mais claras de como fazer a integração, como ela deve ser gerida, incentivada e quais procedimentos a gestão deve adotar para que ela seja fortalecida. Ou seja, não está explicitado, nem com base nas experiências nem há diretivas mais 
objetivas sobre quais procedimentos adotar para viabilizar no dia a dia o EM integrado à EPTNM.

Além da falta de orientações sobre o como da fazer da integração, os relatos indicam situações que dificultam a sua viabilidade, de modo a fazer convergir as pessoas, os tempos, os espaços e os conteúdos. O primeiro obstáculo refere-se a não saberem integrar os conteúdos de diferentes campos do saber escolar. Segundo uma docente do curso de edificações que afirma "A gente tem que aprender a integrar... eu não sei integrar com a educação física, por exemplo...isso pode acontecer com outras disciplinas também".

Em paralelo, ou outro docente, mais antigo da instituição, afirma que

"na época da escola técnica, só havia oferta de cursos técnicos e todos os professores e alunos estavam envolvidos como docentes e ou discentes de cursos técnico - profissionalizante de $2^{\circ}$ grau. Hoje trabalhamos com vários tipos de cursos diferentes" (Grupo focal 02 - Vitória / Edificações - 21/11/2013).

Uma reclamação constante dos professores é a falta de oportunidade de encontros entre eles: "a gente só tem esses encontros no conselho de classe que é só nota e falta, nota e falta, a parte do conteúdo a instituição não propicia esses momentos de encontro" (Grupo focal 01 - Vitória / Eletrotécnica - 13/03/2013).

Ou seja, a escassez de encontros impede maior integração e desse modo fica difícil fazer confluir os tempos, os espaços e os conteúdos de ensino no sentido da construção coletiva de iniciativas que levam à interdisciplinaridade e à integração. Por outro lado, a administração não tem mobilizado de maneira eficaz os docentes neste sentido, de modo que cada um vai desenvolvendo o seu conteúdo sem necessariamente relacionar-se com os colegas. Faz-se sobreposição de conteúdos e as avaliações demandam cada vez mais dos alunos que precisam saber administrar 14 disciplinas por ano/série com provas e atividades desconectadas entre si.

A tendência que percebemos nos relatos é que a operacionalização da matriz curricular integrada combina dois processos: a fragmentação e a justaposição. A fragmentação tem a ver com os tempos, os conteúdos, as pessoas e os espaços. Isso ocorre quando cada docente, por sua formação e por sua rotina de trabalho, cuida do que ensina fazendo a partir de uma sequência didática que se enquadra nos limites de tempos e espaços. A justaposição tem 
mais a ver com os conteúdos e avaliações que se empilham, se juntam na cabeça dos alunos, mas não se articulam se não pelo esforço dos discentes em fazer as relações entre os diversos saberes que compõem a totalidade da realidade.

A própria administração dos campi também está multifocada tendo que administrar um grande número de alunos e diversos tipos de curso. Os gestores e docentes se perguntam o que fazer para criar estratégias de trabalho de gestão que fortaleçam os cursos integrados. Se a instituição tornou-se uma entidade pública híbrida, com atribuições em todos os níveis e que atende a muitas demandas diferenciadas, a coordenação e corpo pedagógico, em conjunto com os docentes, precisam traçar estratégias para dar conta desse processo.

Além disso é notável a necessidade de valorização das práticas integradoras já mobilizadas por alguns docentes, reconhecendo a importância das iniciativas particulares como forma de romper o isolamento assim como a necessidade da realização de pesquisas que se propõem a promover a formação para produção da integração.

Por demanda dos participantes dos grupos focais foram emergindo solicitações de intervenção para realização da integração. Ao longo das reuniões os participantes, reconhecendo os limites e a necessidade de avançar em direção a uma prática mais integrada, foram demandando ações mais concretas chegando a indicarem algumas propostas, ainda que difusas: "Eu pensei em a gente fazer um seminário. Dois dias... Porque tem muita coisa" (Grupo Focal 04 São Mateus - 29/07/2014).

Assim, no ano de 2015 o campus São Mateus, em colaboração com a pesquisa, foi realizado o evento "Formação Pedagógica 2015: Diálogos sobre a Educação Profissional e Tecnológica", como objetivos proporcionar espaços de formação continuada com vistas a qualificar o ensino ofertado pelo campus. $O$ evento realizado em dois dias teve a participação de uma média de cem pessoas em cada dia e envolvendo público externo e interno do município onde se localiza o campus.

Apesar de verificarmos inúmeras práticas de integração já realizadas pelos professores dos diversos campi, muitos posicionamentos indicavam a necessidade de mudanças na gestão para fazer evoluir a integração. Os docentes passaram a demandar da pesquisa uma atuação mais diretiva e não apenas formativa, de modo a trazer uma proposta que viabilizasse no ensino e no

TrabalhoNecessário- www.uff.br/revistatrabalhonecessario: ano 16, №29/2018 
currículo praticado avanços na integração. Tais posicionamentos se repetiram na realização das reuniões dos grupos focais nos diversos campi com destaque para os campi São Mateus e Vitória onde a pesquisa-ação se desenvolveu de modo mais participativo e por mais tempo, com mais reuniões e de forma mais orgânica.

Majoritariamente os grupos focais afirmavam que: mesmo que a integração pudesse se dar na cabeça do aluno ou que existissem iniciativas pontuais de trabalho interdisciplinar ou mesmo que as matrizes curriculares previssem o ensino uma ou outra disciplina denominada como projeto integrador, isso era insuficiente. Pois, não havia uma proposta mais elaborada e mais sistêmica para fazer a integração e que fosse capaz de tirá-los do comodismo de trabalhar de modo isolado:

\begin{abstract}
Eu compreendo a angústia que nos é causada por não saber fazer. A gente não sabe fazer e o comodismo do lugar quentinho que a gente já é acostumado é difícil tirar a gente dali. Eu compreendo. Mas se tiver como fazer, tem que fazer (risos) (Grupo Focal 04 - São Mateus - 01/12/2014).

Acho que pra funcionar teria que ter alguém cuidando dessa integração. (Grupo focal 01 - Vitória / Eletrotécnica - 03/12/2014).

Vamos fazer um projeto para isso...nós precisamos que haja a integração dos conteúdos (Grupo focal 01 - Vitória / Eletrotécnica 03/12/2013).
\end{abstract}

Assim, a partir da identificação da demanda elaboramos uma proposta de intervenção que consistia em um projeto de integração. Tal movimento da pesquisa nos colocaria numa nova situação de fazer não apenas uma pesquisaação formação, mas uma pesquisa intervenção.

O passo seguinte foi a apresentação aos participantes de um projeto que não se propôs em momento algum a ser uma receita para dar conta da integração do ensino médio com o ensino técnico no IFES. Com base nos elementos trazidos pela pesquisa foi elaborada uma dinâmica colaborativa para realização da integração que continham diretrizes gerais resumidas em 10 ações que visavam fazer a gestão organizar e fomentar ações de integração no sentido de dar mais sistematicidade, às inciativas concretas de integração, colocando alunos e professores como protagonistas dessas experiências de ensino e aprendizagem.

Em síntese, a proposta consistia ações necessárias à integração e que deveriam nortear a experimentação da integração através de atividades a serem 
01 - Fazer diagnóstico e avaliação da integração curricular no campus e no curso integrado no contexto dos indicadores do curso (candidatovaga, fluxo escolar - retenção escolar, $n^{\circ}$ de disciplinas e $n^{\circ}$ de avaliações);

02 - Realizar estudos e debates sobre as bases teóricas e legais da integração curricular com aprofundamento de estudos sobre os conceitos de: - Currículo como Totalidade Orgânica / - Trabalho como princípio Educativo; - Pesquisa como princípio pedagógico / Eixos curriculares (Cultura, Trabalho, Ciência, Tecnologia, Sociedade e Meio Ambiente); Interdisciplinaridade; - Temas Problematizadores e globalizantes / Nexo Integrador;

03 - Sortear e montar equipes interdisciplinares com 04 professores $(02$ da educação geral e 02 da educação técnica) que atuam nas mesmas turmas e nos mesmos anos-séries dos mesmos cursos;

04 - Escolher e elaborar proposta de atividade de integração - Envolver as disciplinas e professores envolvidos (sorteados), pode ser: - Atividade de ensino (Desenvolvimento de processos e ou Geração de produtos a serem desenvolvidos com a participação dos alunos - Projeto de pesquisa / Projeto de extensão - Visitas técnicas / Relato de experiências;

05 - Elaborar plano de trabalho com cronograma, equipe de trabalho (professores e alunos), material de consumo e recursos financeiros e logísticos necessários;

06 - Apresentar as propostas de trabalho das equipes para 2015 para avaliação e discussão no grupo com todos os docentes da educação geral (propedêutica) e da educação específica (técnica) e gestores do IFES;

07 - Providenciar recursos e dar início as atividades integradoras propostas; aprofundar os estudos em sala de aula dos conteúdos das disciplina na sua relação com o tema, eixo e ou nexo integrador;

08 - Realizar atividade de integração, produzir relatório e realizar coletivamente avaliação das 04 disciplinas verificando a aprendizagem das turmas participantes;

09 - Realizar exposição, seminário, feira, apresentação de pôster e relatos das atividades de integração;

10 - Publicação no site da instituição das experiências de integração com certificação da UFES e IFES de alunos e profissionais envolvidos. (projeto formulado coletivamente no processo de pesquisa ver em: Relatório de pesquisa PIIC UFES PRPPG 2015http://portais4.ufes.br/posgrad/anais_jornada_ic/).

$\mathrm{Na}$ essência, a proposta buscava criar a oportunidade para que equipes compostas aleatoriamente por docentes da base nacional comum, da parte diversificada e do ensino técnico realizassem, em uma turma, uma vez por ano, 
um projeto integrador que deveria permitir aos alunos a participação em atividades comuns de ensino, pesquisa ou extensão.

Uma vez implementada a proposta em cada série-curso-ano de cada campus dever-se-ia incorporar todos os docentes os quais deveriam se automobilizar com ajuda das coordenadorias, setores pedagógicos e de apoio ao aluno bem como diretoria de extensão para viabilizar os projetos interdisciplinares/integradores, as visitas técnicas, os projetos de pesquisa e ou de extensão. Para tanto seria necessário propiciar espaços tempos no cotidiano dos campi para integração das pessoas e dar suporte aos projetos que deveriam emergir das equipes que seriam montadas por sorteio.

No entanto, logo na apresentação da proposta nos deparamos com as primeiras tensões do processo de pesquisa-ação que sinalizaram que não bastaria existir uma proposta considerada razoável e exequível de integração. Era preciso que os professores e gestores se envolvessem no aprofundamento teórico sobre os fundamentos da integração curricular, pois a medida que o prosseguimento da pesquisa passou a exigir o protagonismo desses profissionais nos grupos focais a integração necessária entre alguns indivíduos se mostrou pouco promissora e as agendas de reunião começaram a ser reduzida.

Assim, apenas nos campi Vitória e São Mateus o trabalho evoluiu para a montagem das equipes (Ação 3), mas o critério de composição das equipes foi contestado, demonstrando os limites de integração entre as pessoas, e em alguns casos uma recusa à proposta, o que de certo modo refletia a dificuldade dos participantes em pensar o trabalho com profissionais de outras áreas.

então eu penso que se alguns desses problemas que nós já identificamos não poderiam guiar essa construção das equipes invés do sorteio, por que o sorteio eu penso que talvez a gente corresse mais esse risco...então se a gente pudesse seguir as afinidades talvez o efeito fosse mais rápido mais sensível nesse primeiro momento. (Grupo focal 02 - Vitória / Edificações 13/11/2014).

Outro elemento nos chamou a atenção foi a inquietação de alguns participantes diante da possibilidade de ter que abrir mão de parte da sequência didática, da carga horária e dos conteúdos de suas próprias matérias de ensino para a realização do projeto de integração. 
eu na minha aula vou ter que estar voltado para esse projeto, falando desse projeto, desenvolvendo esse projeto naquele determinado período? [...] tá correto, agora a minha pergunta é: eu sou professor de química do primeiro ano, no nosso curso de edificações...nós temos duas aulas, a gente já corre e sofre pra dar pra conseguir contemplar a disciplina né do primeiro período, isso foi pensado? [...] minha preocupação é essa de não conseguir fechar o conteúdo (Grupo focal 02 - Vitória / Edificações - 13/11/2014).

A preocupação expressa na fala carrega uma tradição historicamente construída que se preocupa muito com o cumprimento dos conteúdos e menos com a qualidade com que são aprendidos. Refletem ainda uma dificuldade de compreensão de que na integração os conteúdos continuariam a ser ensinados, mas numa forma diferente da que vinha sendo realizada habitualmente.

Outro elemento que provocou tensões no grupo e que demonstrou o quanto a organização hierarquizada dos saberes configura-se como uma barreira a ser transposta no processo de integração foi a demanda de mobilização de uma série de conceitos que diferiam da forma como estes estavam organizados nas ementas das disciplinas, pressupondo quebrar a sequência e a forma com a qual os participantes estavam acostumados trabalhar.

Após a montagem dos grupos, a etapa seguinte consistiria no planejamento da atividade de integração (Ações 4 e 5) que deveria ser supervisionada e orientada pela equipe pedagógica dos campi. Após a finalização dessa atividade, retornaríamos as reuniões do grupo de pesquisa para que as equipes socializassem (Ação 6).

Nesse momento surgiram mais dificuldades, pois se antes nosso trabalho nos campi era demandada pelos participantes, a partir desse momento o retorno passou a não ocorrer da mesma forma. Tanto os docentes quanto a equipe pedagógica, quando solicitados a elaborarem as atividades (o que pressupunha rever os planejamentos das disciplinas, fazer o reposicionamento de conteúdos e alterações em sequências didáticas pré-estabelecidas, ou seja, o movimento de fazer aquilo que não estava dentro de sua rotina) afastaram-se do processo de pesquisa e em alguns campi chegaram a esvaziá-lo.

Nesse contexto optamos pela interrupção da pesquisa e propomos uma avaliação do processo e dos rumos da mesma, dado que para a pesquisa-ação é fundamental pesquisadores e sujeitos participem de maneira equiparada. Buscamos realizar reuniões com essa finalidade e, para nossa surpresa, permanecia a vontade de uma intervenção sobre a questão da integração, no

TrabalhoNecessário- www.uff.br/revistatrabalhonecessario: ano 16, №29/2018 
entanto permanecia a resistência em abrir mão do que já estava planejado ou do que já era habitual no cotidiano dos docentes e pedagogos.

Ao final dessa etapa, consideramos que a ansiedade de encontrar uma solução que auxiliasse na ruptura de uma cultura de desintegração praticada no ensino médio integrado, natural entre aqueles que almejam a transformação dessa modalidade a serviço de uma formação mais humana e integral, nos conduziu ao equívoco de não avaliarmos que a resistência praticada pelos participantes era o reflexo de uma tradição de desintegração inscrita na história escolar e na vida acadêmica que cada um daqueles sujeitos carregava.

Para sistematizar os resultados da pesquisa elencamos os seguintes aspectos: $\mathrm{O}$ pressuposto da pesquisa, o diagnóstico gerado pela pesquisa, os resultados da pesquisa-ação-formação, os resultados pesquisa-ação-intervenção e a produção acadêmica.

Pressuposto da pesquisa - Relação efetiva entre frágil formação pedagógica do corpo docente e improvisação da prática de integração e consequente tendência de queda ou restrição da oferta de matrículas do ensino médio integrado: integração $X$ verticalização (heterogeneidade para cima e para baixo - Ver Lima 2016); e falta de identidade docente.

Diagnóstico: Falta de sintonia, de sinergia e de conhecimento do andamento do ensino desenvolvido pelos outros docentes de outras disciplinas com as mesmas turmas dos cursos técnicos integrados; dispersão, pouca visibilidade e valorização das experiências de integração das disciplinas dos cursos técnicos integrados; e prática de ensino fragmentada e processo de aprendizagem em justaposição (empilhamento de conteúdos/sobrecarga avaliações).

Pesquisa-ação-formação - Mobilização e Discussão dos grupos focais nos campi de Vitória, Venda Nova do Imigrante, Colatina, São Mateus, Barra de São Francisco, Cariacica e Guarapari nos cursos de Agroindústria, Administração, Eletrotécnica, Mecânica e Edificações; debate sobre a oferta de matrículas do ensino médio integrado: tendências, objetivos, dificuldades e potencialidades; problematização sobre a integração dos docentes, dos conteúdos, dos espaços e do tempos dos cursos técnicos integrados; ampla aceitação e concordância sobre necessidade da formação, mas pouca continuidade do processo de debate sobre a integração curricular; desmobilização dos grupos focais nos campi Venda Nova

TrabalhoNecessário- www.uff.br/revistatrabalhonecessario: ano 16, №29/2018 
do Imigrante e Colatina; e Relativo envolvimento dos campi de São Mateus e Vitória.

Pesquisa-ação-intervenção - Demanda dos grupos focais pela elaboração de uma metodologia de integração curricular abrangente; projeto de intervenção: montar semestral ou anualmente várias equipes aleatórias (por sorteio) compostas de 02 a 04 docentes e disciplinas pertencentes a um determinado curso e turma a fim de realizar de modo planejado atividades integradas (aula de campo, pesquisa, extensão, visitas técnicas), abrangendo ensino-aprendizagemavaliação. Aceitação inicial nos campi de Vitória, Venda Nova do Imigrante, Colatina e São Mateus.

Produção acadêmica - Promoção de várias reuniões para debater a integração (questões legais, fundamentação e diagnóstico); Evidência das práticas integradoras e reconhecimento dos docentes da complexidade da integração com mobilização incipiente dos professores do ensino médio e técnico em torno do tema; Discussão da relação entre as demandas e desempenho discentes com a falta de integração com destaque das demandas escolares sobre a gestão dos cursos e campi; e apresentação de trabalhos em eventos (Anped, Histedbr, Rede Estrado, Colóquio de Natal-IFRN); Publicação de 02 artigos em revista B2 (Boletim Senac e Revista Brasileira-Argentina do IFBA).

\section{Considerações: os limites e as possibilidades da pesquisa}

O desenvolvimento da pesquisa realizada no IFES foi atravessado por várias questões que impactaram a capacidade da investigação para fortalecer o processo de integração nos cursos ofertados. Tais questões limitaram, mas não impediram reflexos positivos do processo de pesquisa-formação que pautou nas unidades de ensino o tema da integração, contribuindo para a superação dos processos de fragmentação e justaposição curricular.

Destaca-se a importância do comprometimento da equipe de gestão pedagógica de cada campus no desenvolvimento da pesquisa-ação. $O$ trabalho dessas equipes foi fundamental na mobilização dos docentes e da comunidade escolar em geral em torno do tema. Nos campi em que houve um enfraquecimento do trabalho desse setor, a pesquisa perdeu força e viabilidade. 
A grande limitação da pesquisa-ação refere-se as dificuldades que os docentes manifestaram no momento em que tinham que mudar a sua rotina curricular, bem como em trabalhar com os outros colegas segundo a proposta de formação das equipes interdisciplinares, realizada por sorteio.

Ou seja, mesmo relatando seu desconhecimento sobre como integrar, ou suas experiências exitosas, ou, ainda, admitindo o isolamento de sua ação pedagógica, os docentes apresentaram dificuldades em realizar o projeto de integração da pesquisa que eles mesmos demandaram.

Desse modo, no momento em que a participação na pesquisa-formação passou a exigir alterações naquilo que habitualmente costumavam fazer, os docentes exerceram uma resistência muda, demonstrando que não basta querer integrar ou saber seus fundamentos. Permanece na prática o isolamento no processo de trabalho docente que reforça a fragmentação do ensino.

A descontinuidade dos encontros também se colocou como problema, acrescido da rotatividade dos presentes nas reuniões, o que se deve em parte ao maior prestígio de outras atividades acadêmicas vinculadas a demais modalidades de ensino (graduação, pós-graduação e pronatec), gerando dificuldades no processo de mobilização e envolvimento dos docentes.

Entende-se que muitos são os caminhos a serem percorridos para a construção da verdadeira integração do EM à EPTNM. No entanto, os desafios encontrados não constituem impeditivo para o alcance dessa meta nem mesmo depõem contra a pesquisa-ação e ou contra a perspectiva teórica pautada no materialismo histórico-dialético. Ao contrário, a situação em tela fornece pistas para a compreensão da viabilidade de um projeto de integração pautado no comprometimento de todos envolvidos.

Apesar dos méritos intrínsecos da proposta teórico-metodológica que se constituiu na relação da pesquisa-ação, com o compromisso ético-político de transformação da realidade (fortalecimento da integração curricular), a efetivação do ensino médio integrado demanda (no interior da realidade estudada): reconstrução das identidades docente e institucional; valorização do ensino médio integrado como modalidade estruturante dos campi dos IFs; protagonismo de docentes e discentes na integração curricular; e, compromisso das gestões em promover a formação permanente a fim de superar as dicotomias e distanciamentos entre as pessoas, disciplinas, espaços e tempos escolares. 


\section{Referências}

BARBIER, R. Pesquisa-ação. Brasília: Libre livro, 2007.

BRASIL. Lei Federal no 9.394, de 20 de dezembro de 1996. Estabelece as diretrizes e bases da educação nacional. Diário Oficial da União: Brasília, 23 de dezembro de 1996.

30.12.2008.

Lei no 11.892. Criação dos Institutos Federais Brasília: DOU de

. Lei no 13.005 Plano Nacional de Educação Brasília: DOU de 25 DE JUNHO DE 2014.

- Ministério da Educação (MEC). Conselho Nacional de Educação. Resolução CNE/CEB no 6, de 20 de setembro de 2012. DOU: Brasília, 21/09/2012.

BREMER, M. A. S.; KUENZER, A. Z. Ensino médio integrado: uma história de contradições. Trabalho apresentado no Anped Sul: Seminário de Pesquisa em Educação da Região Sul, 2012. Disponível em:

$<$ http://www.ucs.br/etc/conferencias/index.php/anpedsul/9anpedsul/paper/viewFile /2217/208>. Acesso em: set. 2013.

CIAVATTA, M. O conhecimento histórico e o problema teórico-metodológico das mediações. In: FRIGOTTO, G.; CIAVATTA, M. (Orgs). Teoria e educação no labirinto do capital. $2^{\circ}$ ed. São Paulo: Expressão Popular, 2014. p. $191-231$

CIAVATTA, M.; RAMOS, M. N. Ensino médio e educação profissional no Brasil: dualidade e fragmentação. Revista Retratos da Escola, Brasília, DF, v. 5, n. 8, p. 27-41, jan./jun. 2011.

CIAVATTA, M; RAMOS, M. Ensino Médio Integrado. In: CALDART, R S; PEREIRA, I B; ALENTEJANO, P; FRIGOTTO, G. (Orgs.) Dicionário da Educação do Campo. págs. 307-315. Rio de Janeiro, São Paulo: Escola Politécnica de Saúde Joaquim Venâncio, Expressão Popular, 2012.

DINIZ-PEREIRA, J E; ZEICHNER, K M (orgs) A pesquisa-ação na formação e no trabalho docente. Belo Horizonte: Autêntica, 2011.

FRIGOTTO, G. Educação Omnilateral. In: CALDART, R S; PEREIRA, I B; ALENTEJANO, P; FRIGOTTO, G. (Orgs.) Dicionário da Educação do Campo. págs. 267-274. Rio de Janeiro, São Paulo: Escola Politécnica de Saúde Joaquim Venâncio, Expressão Popular, 2012.

HÚNGARO, E.M. A questão do método na constituição da teoria social de Marx. In: CUNHA, C; SOUZA; J.V; SILVA, M.A. (Orgs). O método dialético na pesquisa em educação. Campinas: Autores Associados, 2014. p. 15 - 78. 
IFES. Edital do Processo seletivo dos Cursos Técnicos Multicampi $n^{\circ}$ 01/2016. Disponível em: < http://www.ifes.edu.br/processosseletivos/item/2000-ps-1-2016cursos-tecnicos-multicampi>. Acesso em: 20 Ago 2016.

Quadro de oferta de cursos SISTEC/MEC 2011. Disponível em: < www2.camara.leg.br/atividade-legislativa/comissoes/comissoes.../ce/.../view>. Acesso em: 20 dez 2015.

- Relatório Gestão de 2012. Vitória-ES, 2013. Disponível em:< http://prodi.ifes.edu.br/prodi/Planejamento_Estrategico/Documentos/Relatorio_de_ Gestao_2012.pdf> Acesso em 10 set 2015.

LIMA, M. Relatório de pesquisa / jornada científica. Vitória: PRPPG-UFES, 2014 $<$ http://portais4.ufes.br/posgrad/anais jornada ic/) Acesso em 20-11-2016. >>

Trabalho e educação no Brasil: da formação para mercado da formação. CRV: Curitiba, 2016.

MARX, K. Contribuição à crítica da economia política. $2^{\circ}$ ed. São Paulo: Expressão Popular. 2008.

MONTEIRO, S.B. et al. Considerações críticas sobre a concepção de pesquisaação em Joe Kincheloe. In: Anais da reunião anual da associação nacional de pós-graduação e pesquisa em educação, 21, 1997, Caxambu: ANPED, 2004. p. 01-06 disponível em : <http://www.anped.org.br/reunioes/23/textos/0406p.PDF > Acesso em 15 mar. 2013.

NETTO, J.P. Introdução ao Estudo do Método de Marx. $1^{\circ}$ ed. São Paulo: Expressão Popular, 2011.

RAMOS, Marise. Ensino Médio Integrado: da Conceituação à Operacionalização. In: Cadernos de Pesquisa em Educação - PPGE/UFES. V. 19, ํo 39, p. 15 - 29, jan./jun. 2014.

RAMOS, Marise. Possibilidades e desafios na organização do currículo integrado. In: FRIGOTTO, Gaudêncio; CIAVATTA, Maria; RAMOS, Marise. Ensino médio integrado: concepções e contradições. 3.ed. - págs. 107-128. São Paulo: Cortez, 2012.

SAVIANI, D. O choque teórico da politecnia. In: Revista Trabalho, Educação e Saúde. EPSJV/FIOCRUZ. n. 1, vol. 1. mar.-jul. Rio de Janeiro, 2003.

SAVIANI, D. Sobre a concepção de politecnia. Rio de Janeiro: FIOCRUZ. Politécnico da Saúde Joaquim Venâncio, 1989.

SILVA, M. R. A política de integração curricular no âmbito do proeja: entre discursos, sujeitos e práticas. In: Ensaio: avaliação e políticas públicas em educação, Rio de Janeiro, v. 19, n. 71, p. 307-326, abr./jun. 2011.

THIOLLENT, M. Metodologia da Pesquisa-Ação. São Paulo: Cortez, 1998. 
TRIPP, D. Pesquisa-ação: uma introdução metodológica. In: Revista Educação e Pesquisa, n.3, V.31, 2005.

Recebido em: 23 de outubro de 2018.

Aprovado em: 18 de março de 2018.

Publicado em: 13 de junho de 2018. 